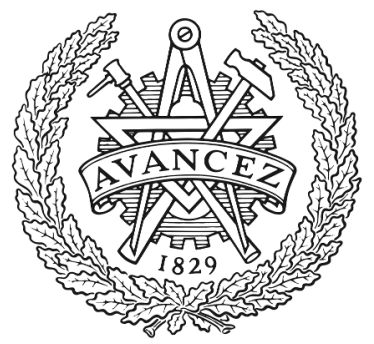

CHALMERS

UNIVERSITY OF TECHNOLOGY

\title{
"Lunch Keeps People Apart": The Role of English for Social Interaction in a Multilingual Academic Workplace
}

Downloaded from: https://research.chalmers.se, 2023-04-26 13:41 UTC

Citation for the original published paper (version of record):

Negretti, R., Garcia-Yeste, M. (2015). "Lunch Keeps People Apart": The Role of English for Social Interaction in a Multilingual

Academic Workplace. Multilingua, Volume 34(Issue 1): 93-118.

http://dx.doi.org/10.1515/multi-2014-0038

N.B. When citing this work, cite the original published paper. 


\title{
Raffaella Negretti* and Miguel Garcia-Yeste "Lunch Keeps People Apart": The Role of English for Social Interaction in a Multilingual Academic Workplace
}

\begin{abstract}
Research on the role of language in multilingual workplaces, where English is often adopted as a lingua franca (ELF), shows that language practices influence socialization and interpersonal communication, frequently creating issues such as asymmetrical sharing of information, language clusters, or thin communication. Similarly to other organizations, academic workplaces are undergoing a process of internationalization. However, academia as a workplace has been largely ignored, particularly in terms of language practices in social situations. We address this gap by investigating multilingualism in an academic workplace; departing from the concepts of language clustering and thin communication, we focus on how language practices affect social interaction and the establishment of rapport. We report the experiences of five academics with various backgrounds and status in a science university department in Sweden. In-depth interviews and grand/mini tour elicitation techniques reveal how language practices - English and other languages - are experienced from different points of view. We identify lunch as the primary activity associated with social interaction and exchange of information: people and places connected with this activity seem to determine language practices. In the final section we discuss the presence of language clustering and thin communication in this academic workplace.
\end{abstract}

Keywords: multilingualism, language practices, socialization, ELF, workplace communication

DOI 10.1515/multi-2014-0038

\footnotetext{
*Corresponding author: Raffaella Negretti, Department of English, Stockholm University, Stockholm University, House E, Stockholm 106-91, Sweden, E-mail: raffaella.negretti@english.su.se. http://orcid.org/0000-0003-1948-1775

Miguel Garcia-Yeste, Department of English, Stockholm University, Stockholm University, House E, Stockholm 106-91, Sweden, E-mail: miguel.garcia@sprak.gu.se
} 


\section{Introduction}

Angouri (2014: 1) stresses that "the modern workplace is international and multilingual": the complex ecosystem of languages that increasingly characterizes workplaces across organizations and public institutions requires a research approach that is sensitive to the contextual dynamics of language use, policy, and ideology. For the past 20 years, language practices in multilingual workplaces have been the focus of various strands of research in business/organizational contexts (e.g. Angouri \& Bargiela-Chiappini 2011; Angouri \& Miglbauer 2013; van den Born \& Peltokorpi 2010; Lauring 2007; Marschan-Piekkari et al. 1999; Peltokorpi \& Vaara 2012; Welch et al. 2005). This work has highlighted important aspects tied to the co-existence of multiple languages in the workplace, including the ideological underpinnings of language management (Lønsmann 2014; Spolsky 2004), the power imbalances associated with language policies and practices (Tange \& Lauring 2009), and the contradictory if not conflictual nature of the relationship between language policies, the use of English, and the actual communicative situations workers engage in (Canagarajah 2013; Fredriksson et al. 2006). The studies show the non-neutrality of language choices in informal situations. Language plays a key role in socialization, the establishment of rapport, and exchange of information but - conversely - may also lead to exclusion, clustering, and hidden power imbalances. The use of English and other language practices for social interaction are the focus of our study, which investigates multilingualism in an academic workplace.

Similarly to other organizations, academic workplaces are undergoing a process of internationalization and globalization, creating an increased need for English-medium education (Kuteeva 2013), and entailing the adoption of English as a communicative lingua franca (ELF) (Björkman 2011, 2013; Tange 2010). Research has underscored the need to look at how national language policies are realized in the local context through diverse language practices and the use of English as a transcultural language (Hult 2012). In fact, language in the university setting has been explored extensively in the Nordic countries. For instance, in Denmark, many researchers have problematized among other things the ideological underpinnings of English as an academic lingua franca, the relationship between policy and everyday practice, and the challenges posed by multilingualism in teaching and learning (see Mortensen \& Haberland 2012; Preisler 2003; Tange 2012a).

In Sweden, the multilingual situation of university workplaces has generated some debate, especially in relation to issues pertaining to the adoption of English in professional academic discourse (Gunnarson 2001, 2009). Other recent research 
that has analyzed language practices in context suggests that the situation of English use in Swedish universities that aim for parallel language practices can be somewhat multifaceted. For instance, drawing from a large survey at Stockholm University, Bolton \& Kuteeva (2012) show that aspects of disciplinary variation and academic level affect specific language practices, with the use of English ranging from very common in certain disciplinary domains, such as the sciences, to almost absent. Similarly, Kuteeva \& Airey (2013) question the adoption of one-size-fits-all parallel language policies, as these do not reflect the need for disciplinary variation; furthermore, these policies are open for interpretation and are not strictly translated into specific practices in Swedish universities, something highlighted also by Björkman's (2014) comparative analysis of Swedish universities' policy documents. One problem, as Kuteeva (2014) suggests, is that the use of English as an academic language in Sweden may implicitly convey attitudes and ideologies biased toward a counter-productive standard of nativeness. Research on contextualized language practices in Swedish universities has focused on ELF and communicative learning strategies among students (Björkman 2013, 2011) or ELF as the language for teaching and learning (Airey 2011; Söderlundh 2012). These studies underscore the fact that students and teachers are quite flexible in translating language policies into a variety of practices that best suit their communicative needs (see Hult 2012). However, less attention has been given to social situations when English or other languages may be used for interactional purposes in the university as a workplace.

In multilingual university settings, language practices not only affect teaching and learning but also the workers' ability to informally interact and thereby socialize, establishing “collegiality” (Nelson 2014) and an overall favorable "social climate” (Lauring \& Selmer 2011) in the work environment. This aspect of socialization has not been at the center of studies on language practices in universities, although research on language in universities has provided incidental evidence of its importance. In a study on "kitchen talk" among students, Hazel \& Mortensen (2013) for instance suggest that students in an international, multilingual program need to develop interactional competencies to fully function in non-institutional situations. Similarly, Tange (2012b: 10, emphasis added) suggests that "the adoption of English has influenced lecturers' ability to manage everyday tasks and interaction." Furthermore, some researchers have raised awareness about the potentially negative ideological underpinnings tied to the use of ELF, arguing that the use of a lingua franca in multilingual settings is not in fact a neutral choice and that more attention needs to be devoted to localized linguistic practices: "Communication is always embedded in and constitutive of social situations and involves speakers with purposes and positions” (Baker 2011: 199). Thus, there is still the need to investigate the interactional, "micro" aspects of multilingualism 
in the academic workplace: "the ways in which the co-existence of multiple languages is managed at the micro-level by the interactants" (Angouri 2014: 2), for instance in social situations and informal communication.

In this study, we adopt an ethnographic approach to explore the language practices associated with informal interaction and socialization in a multilingual academic workplace in a Swedish university, by focusing on individuals' choices and experiences. Given that social interaction is of vital importance for sociocultural adjustment and establishment of rapport (Spencer-Oatey 2002; SpencerOatey \& Xiong 2006), our aim is to investigate how various language choices influence socialization: how faculty with different backgrounds and positions within a Swedish academic institution make use of English and other linguistic resources to network, take part in social activities, negotiate belonging to a group, and generally do "relational work" (Locher \& Watts 2005). Specifically, we explore whether issues tied to language use in informal social interaction identified in business organizations, such as language clustering and thin communication (Tange \& Lauring 2009), may also apply to multilingual academic workplaces.

Adopting exploratory interviewing techniques of grand tour and mini tour, our primary aim is to elicit an initial understanding of the communicative and linguistic practices as experienced by individuals of different status and with different first languages and to provide a contextualized perspective on the micro-level facets of "multilingualism at work" (Angouri 2014: 3): how language affects the social dimensions of their workplace reality.

\subsection{Language and social interaction in the multilingual workplace}

Multilingual workplaces are clearly a type of context where people from different backgrounds are faced with the need to cooperate and negotiate professional tasks, often requiring them to confront issues of intercultural communication and language practices (Angouri \& Miglbauer 2013). A consistent body of research has investigated language and communication problems in business or institutional workplaces that often adopt English as a lingua franca, showing the relevance of establishing social relationships in the workplace through informal communication, small talk, and pragmatic negotiation (e.g. Angouri 2012; Marschan-Piekkari et al. 1999; Pullin 2010). Some of the major communication issues in a multilingual workplace occur in situations of social interaction and are tied to the power imbalances and inconsistent, if not unequal, flow of information that language practices may create. 
As pointed out by Bjørge and Whittaker (2011: 2), there is a need to further explore the role that language plays in workplace communication, as "the challenges faced by linguistically diverse organizations with regards to communication are rarely taken into account." Summarizing the existing research in Norway, they explore the implications of language management on external and internal communication. As of $2010,10 \%$ of the Norwegian workforce consisted of highly skilled immigrant workers employed in multinational companies where ELF is adopted for external and internal communication. The authors underscore the implications of a situation that forces most of the workforce (including the local Norwegians) to communicate in a language different from their mother tongue. Among other issues, Bjørge \& Whittaker (2011) point out that, given the importance of communication, language often plays a decisive role in the establishment of group boundaries and may lead to shadow power structures and unofficial channels of communication as well as serve as an instrument of exclusion/inclusion, especially in informal social interaction. Similarly, studies in Finnish (Welch et al. 2005) and Danish organizations (Tange \& Lauring 2009) stress the fact that language - whether English or the local language - may create hurdles to effective cross-cultural communication, often to the detriment of the less proficient speakers, and most importantly that it has a key role in the establishment of social structures and the distribution of power in the workplace.

A consistent body of research has explored the implications of using ELF in multilingual workplaces and business settings. This research has suggested among other things that the use of ELF may lead to miscommunication and misrepresentation when native speakers are involved (Sweeney \& Hua 2010). Similarly, Rogerson-Revell $(2007,2008)$ focuses on the use of ELF in international business meetings and stresses the linguistic and communicative challenges faced by non-native speakers of English who feel less confident in using English orally, and often remain silent. Recent work by Śliwa and Johansson (in press) shows, for instance, that in international business settings much stigma is still attached to non-native language fluency in English. In an article reviewing research conducted in collaboration with colleagues in Finland, Charles (2007: 271) stresses that in multilingual workplaces the use of ELF does not necessarily facilitate communication, but that language practices, such as the use of English or another language (in our case Swedish), often becomes a power-wielding tool: "informal, oral communication should be considered of paramount importance in multinational companies."

Thus, research points to the need to investigate the role of language in the establishment of relationships at work, and especially the use of informal communication or "small talk" to establish rapport and social connections. In 
a study aimed at creating an inventory of verbal communication behaviors in work contexts, Keyton et al. (2013: 164) were able to demonstrate the importance of "positive social-emotional communication in overcoming communication problems" and in creating work relationships. The work of Angouri and colleagues (Angouri 2010, 2012; Angouri \& Bargiela-Chiappini 2011; Angouri \& Miglbauer 2013) has addressed pragmatic aspects of workplace multilingualism such as problem-solving tasks and disagreement and has illustrated the implications of using English and local languages for integration/belonging, rapport management, and solidarity. This research stresses the need to take a critical look at contextualized practices, rather than attributing communication problems to differences of language and culture, something also advocated by other key figures in intercultural communication pragmatics such as Helen Spencer-Oatey (2002: 533): "If we are to understand how relations are managed, including the role of language in this process, we need to have insights into the social expectancies and judgments of the people involved. It is important, therefore, to include the interactants themselves as a source of data."

Overall, the multidisciplinary research presented so far points to the fact that language is central to the establishment of social relationships at work, as it has implications in terms of power and effective communication. Furthermore, language practices - whether the use of English or another local language may have important implications for an individual's perception of agency and professional identity in the workplace (Canagarajah 2013). These issues merit attention also in academic workplaces, where language use for social interaction is often not officially regulated.

Our paper focuses specifically on two dynamics observed by Tange \& Lauring (2009) in a study on individual experiences of social interaction in a multilingual workplace, namely: language clustering and thin communication. Adopting the concept of language as symbolic power proposed by Bourdieu (1991), they depart from the premise that language is an important tool to establish social structures in the workplace as it allows individuals to achieve power and control, "employees who master the dominant language have access to a range of formal and informal communication channels, enabling them to engage in social bonding across the organization, whereas individuals lacking such linguistic resources find themselves isolated" (Tange \& Lauring 2009: 219). In their study, they maintain that language practices connected to informal communication and small talk - both English and the local (Danish) - create in/out group boundaries and unofficial power structures. Despite the official positive rhetoric toward multilingualism and multiculturalism, social groups tend to cluster around language and culture, with local employees (speakers of Danish who are also highly proficient in English) enjoying the most symbolic 
power within the workplace. Besides linguistic and social fragmentation, this phenomenon results in some workers experiencing a reduction of the opportunities for communication afforded by the workplace, i.e. thin communication. Overall these phenomena affect the quality of the social environment in the workplace, as "informal exchanges represent a mutual effort on behalf of the participants to establish a common, social and cultural platform" (Tange \& Lauring 2009: 227). Thus, in this study, we explore the interplay between language choices and social interaction in an academic workplace. Given the context, this piece of research pays special attention to English as a lingua franca; however, other languages and their roles are considered too.

\section{Method}

\subsection{Context and participants}

The study takes place at a scientific department at a Swedish University. This is a very large institution, which in recent years has grown even further. The staff at this department is typically affiliated with different research groups, partly on the basis of research grants but primarily on the basis of research topic. The department comprises around 70 faculty members from emeriti to doctoral students, and the composition of the staff is very heterogeneous. A quick overview shows a considerable amount of change in the past 30 years or so. Whereas none of the emeriti professors are foreign academics (i.e. they are all Scandinavian), the presence of incoming scientists from other countries shows a steady increase over the years: four out of thirteen professors are foreign, but around half of the researchers (including postdocs) and doctoral students come from other countries. Furthermore, the majority of the staff members are now from countries outside of Europe. A recent study conducted at this university for instance showed that although the university adopted a "parallel language policy", this notion remains rather abstract and that the use of English is quite common in the most scientific and international fields of study (Bolton \& Kuteeva 2012). In fact, our interviews reveal that English plays a central role in the discipline; in some cases, English is used even among speakers of the same language. This multinational and multicultural workplace reality made this department a prime candidate for a study on the role of language in workplace interaction.

Because of the somewhat sensitive nature of the research topic, the first challenge was to gain entry and trust. After contacting the department head, 
the authors were invited to lunch with a few of the staff members and were asked to present the overall research aims. This occasion also provided the opportunity to recruit possible volunteers for the study. We then contacted some of the people present at the lunch, including the head of the department, and asked them if they would be available for an interview. We also asked these participants to nominate other potential participants; that is, we used snowball sampling which, following Dörnyei \& Csizér (2011), is a useful technique when studying groups whose membership is not readily identifiable. In line with the exploratory nature of the study, we created a stratified representative sample of interviewees (see Johnson 1990) which, although small in terms of size, was representative in terms of quality and suitability for our research questions (see McEnery et al. 2006: 19). Five participants were selected, based on status within the department and nationality/first language: one head/professor (Scandinavian), one researcher (Asian), one postdoc (from Central Europe), two doctoral students (one from Southern Europe and one from Asia). It is interesting to note that although these scientists use English as the primary lingua franca in the workplace, none of them is a native speaker of English, and therefore we can hypothesize that the kind of imbalance dynamics pointed out by research on native/non-native speakers in ELF interactions (e.g. Sweeney \& Hua 2010) should not apply to this context.

\subsection{Data collection and analysis}

The aim of the study was to gain an understanding of the role that language especially English - plays in informal interaction and socialization: how and when language is used during the workday, what language is used in relation to certain activities and by whom, how people experience socialization in the workplace, and which language they use to socialize. This kind of information is normally identified as the informants' "tacit knowledge" (Johnson \& Weller 2002: 491), i.e. knowledge that is not necessarily cognitively available to the participants themselves but that is part of their shared, normally unarticulated, personal everyday experiences. In order to gain an insight into this kind of data, in-depth, semi-structured interviews with a conversational approach are necessary (Holstein \& Gubrium 1997), using elicitation techniques typically used in ethnography.

We followed the interview approach proposed by Johnson \& Weller (2002: 500), who stress that appropriate elicitation techniques are especially useful in exploratory studies where the researchers themselves are in the role of learners, i.e. they need to gain an understanding of the context and the phenomena 
associated with it: "researchers' initial interviews should focus on discovering such categories and the terminology used by people in the setting to classify their own thoughts and experience." With this aim in mind, we incorporated the elicitation techniques known as grand tour and mini tour devised by D'Andrade (1976) and Spradley (1979) as described in Johnson \& Weller (2002). Figure 1 provides a synopsis of these techniques and the type of knowledge they aim to elicit.

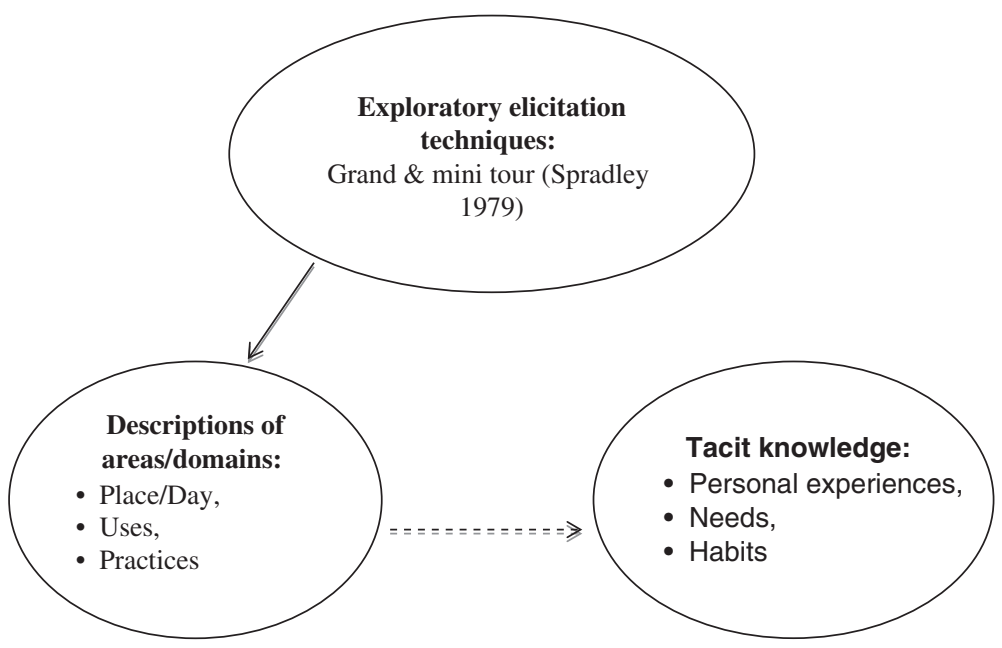

Figure 1: Overview of grand/mini tour elicitation techniques

After a short conversation about their background and their "story" (e.g. how their academic career developed, how they ended up in Sweden, their goals for the future), we asked participants to describe areas or domains typical of their workday: the place where they work (the department), their day, and the activities that take place in relation to language. This "grand tour" phase adopts broad, descriptive questions such as “can you describe your workplace?” or “can you describe your typical day?" that aim to elicit practices, habits, and needs (Johnson \& Weller 2002: 497). In the second part of the interview, the “mini tour", more specific questions were posed about language use in specific activities mentioned in the grand tour, including a free recall task (Johnson \& Weller 2002: 501) where the participants were asked to list all the times in their workday when they used English and with whom.

The collected data amounted to around five hours of interviews, which were carried out in English. After transcribing the data, we independently created 
written interview summaries: close descriptions of what each informant said during the interview, reporting verbatim quotes to illustrate the most interesting points. We then compared these summaries and started to make annotations about common themes across the participants and interesting quotes and phrases. During this comparative analysis we kept an analysis memo to keep track of interpretations and their grounding in the data. Overall, we followed the techniques indicated by Miles \& Huberman (1994: 56), attaching codes in the forms of brief annotations and key words to "chunks of varying size - words, phrases, sentences or whole paragraphs" to characterize the participants' descriptions, commonalities among them, and recurrent expressions. A further comparative analysis of the data was carried out to map out practices and key activities for socialization in the workplace and related language uses: activities, participants, relationships, and settings (see Miles \& Huberman 1994: 61).

\section{Results}

To facilitate the readability of our results, in this section we will first present a narrative about each interview to better illustrate our informants' individual experiences of socialization and language use, with selected quotes to elucidate points made by the informants. Results are reported following the order in which the interviews were conducted; participants have been assigned numbers in order to preserve their anonymity. At the end of this section we summarize the main themes that our informants seem to discuss in relation to socialization, language, and lunch.

\subsection{Informant 1}

Our first interviewee is a Southern European doctoral student who has lived in Sweden for four years. From the interview, it is evident that Informant 1 has a strong motivation to socialize. In fact, his wish to socialize is reflected in some of his remarks (1), and in the fact that he engages in social activities with his co-workers; for example, he regularly plays football with colleagues.

(1) It is important to find friends and establish connections.

(2) When I am outside I prefer to use Swedish and that's also the reason why I started learning Swedish a couple of years ago [...] my feeling was that it was better in order to feel integrated to use the local language. 
His enthusiasm is mainly due to two main causes. On the one hand, given the nature of his research (his topic falls into a slightly different category than that of his closest colleagues), his daily routine keeps him working in isolation; in fact, he mostly interacts with his supervisor and with an external collaborator who is based in Southern Europe. It is interesting to note here that, even though Informant 1 and this external collaborator come from the same Southern European country, because they are both used to talking about science in English, they usually interact in this language and not in their mother tongue. On the other hand, the desire of Informant 1 to stay in Sweden is the main reason why he is learning Swedish. As he explains during the interview, it can sometimes be hard to practice Swedish, as the general level of fluency in English is so high that it is usually easier for him to revert to English when he finds it hard to communicate in Swedish.

In connection to these language issues, Informant 1 points out the importance of the lunch activity for social interaction and its essential connection to language practices. Lunch, for him and the key people associated with an important research group (including the department head), always takes place outside the department, in a restaurant. The conversation is usually carried out in English, and occasionally in Swedish, and is an opportunity not only to socialize and informally discuss work but also to practice and improve one's language skills. Needless to say, it can be a rather uncomfortable situation for someone who does not normally join this group. In fact, he jokes about a ritual the group has whenever someone new joins the department (4); the newcomer is invited to join the group for lunch at the restaurant, and much attention is paid to this new person, whom they therefore nickname "the victim":

(3) Except for special occasions, it is always the same group plus an occasional guest [...] usually if we have a newcomer to the group or the department Informant 3 likes to invite them to join us [...], in this case we call him the victim... because everybody at this, at this time, in this situation - it was also my case at that time - you get lots of attention [...] you get extreme, extremely tired.

In terms of language choice, there are three main aspects that emerge from this interview. First, as part of what we have called the "EU group" - i.e. the group of academics from European backgrounds working in this department - Informant 1 uses English as the main language for work, as well as for socialization with his colleagues. In fact, as mentioned above, he uses English even with his external collaborator, a fact that he explains in reference to their habit of using technical vocabulary in English, rather than their mother tongue. However, using English both as his professional and his socialization language is not exempt from challenges. Informant 1 indicates that using English all day 
long at work was quite overwhelming at the beginning, although it has become easier (4).

(4) Using English all the time can very tiresome, especially at the beginning, but it gets easier with practice [...] I remember the first weeks I was coming home extremely tired and was, really, almost, switched off - but, after a while, you get used to it

Another interesting aspect related to language choices is that, occasionally, Informant 1 uses Swedish with his supervisor (Informant 3). This, however, is only an option when discussing personal matters. The same is true of his interactions outside work. In those contexts, he prefers to use Swedish to become more integrated.

Overall, Informant 1 seems to have had a positive experience of using English and the local language for social interaction in the workplace, and it seems that this willingness - together with his motivation and curiosity toward language learning - has helped him integrate socioculturally in this workplace context.

\subsection{Informant 2}

Informant 2 is an Asian doctoral student, who has spent five years in Sweden working in the research group lead by Informant 3 and another key grant-holder in the department. ${ }^{1}$ He has recently graduated, and is currently looking for a position in Sweden or elsewhere, including Asia and the US. The main rationale behind his choice of country is the kind of position, rather than the country itself.

The lunch experience for this informant is very different from that of Informant 1 . To begin with, Informant 2 has lunch in the lunchroom at the department. In addition, because he does not always have lunch at the same time, the people he interacts with are usually different. Probably related to this constant change, Informant 2 explains that the usual topics of conversation revolve around everyday life in Sweden (e.g. which supermarket offers the best value for money) and world gastronomy (i.e. typical dishes from the national

1 This grant-holder is the deputy head of the department and leader of the research group in which most of our informants work. The grant-holder is originally from Asia; during the interview with Informant 2 it transpired that the grant-holder is a strong advocate of everyone using English in the department. When combined, all these factors place the grant-holder in a position of power in the department; thus, the grant-holder's views on language choices seem to have an impact on the other colleagues, especially on those who work in the same group. 
cuisines of the people present at a particular time). This is because he feels these are safe topics and everyone feels free to interact (5).

(5) The food is the more [common] topic we talk [...] sometimes we also talking about life in Sweden [...] also we also exchange information... which supermarket is discount? or the season comes to the shops, clothes [...] We feel free to talk about these topics.

Another issue that arises in connection with the different lunch partners is language choice. A very good illustration of Informant 2's language choice patterns is his description of lunchtime in the kitchen: he uses his mother tongue if he has his meal with other speakers of the same language, but he uses English, if the group assembled is international. In the latter case, however, Informant 2 expresses his discomfort about the use of English for informal communication, which he sees as a threat, due to potential miscommunication. As he explains (6), his oral English is not very fluent and, therefore, his interpersonal relationships do not hinge on the use of English.

(6) My English is not so good. If the conversation is about other things (not technical) is difficult. Also, most difficult when people's background is different.

Another aspect of Informant 2's language choices is connected to his socialization outside the workplace. Given that his community is rather significant in this department, Informant 2 socializes mostly with other Asian members of the department. In addition, his discomfort using English for socialization seems to encourage him to spend his free time with his fellow compatriots.

\subsection{Informant 3}

Born and raised in Scandinavia, Informant 3 has worked in the department for 40 years and is the current chair. Together with another grant-holder, Informant 3 manages a prestigious research group within the department.

Probably, as part of this position of power, Informant 3 organizes lunch every day with the members of his team. As mentioned by Informant 1, occasional guests are invited to join them, and again it is Informant 3 who invites them. Because lunch for this research group takes place in a restaurant on campus and seems to be very much a set habit, there seems to be a clear division: If you are part of the research group, you have your meal at the restaurant; otherwise, you have lunch at the department (7). This division is recognized by Informant 3, although he does not explain in the interview what the causes might be. 
(7) This division [lunch practices] keeps people apart.

In terms of language choice, Informant 3 is a very interesting case. To begin with, he claims to speak several languages. From these, at work he uses English most of the time and, occasionally, Swedish with his Swedish colleagues.

Furthermore, Informant 3 is very keen on constructing his identity as a language-oriented person. On the one hand, he indicates that he enjoys learning languages, although he emphasizes that he is more interested in understanding how people communicate in a language, how they use that language, and how that language represents culture, rather than learning the grammar of a language or becoming proficient in that language (8).

(8) I think linguistic is more interesting that the language itself. Cultural aspects are more interesting than the language itself.

On the other hand, he has informally appointed himself as the language police of his research group. In this sense, he has two main functions: he corrects everyone's Swedish and English on a regular basis, whether they are communicating for work or socially, and he promotes the local (Swedish) language and culture $(9,10)$. In particular, he offers guided tours around the city to his international colleagues, and he tries to encourage them to learn Swedish as well as providing opportunities for them to practice, as shown in the following comments.

(9) In the past, people learned the local language; now Swedish has almost disappeared.

(10) We usually speak English [at lunch], but sometimes I remember we should speak Swedish because they need to practice to keep up their learning.

Overall, Informant 3 seems to play a key role in the department in terms of power and in terms of language practices. This is particularly evident in social situations such as lunch.

\subsection{Informant 4}

Informant 4 is an Asian tenure-track researcher who has lived in Sweden for four years working in the research group led by Informant 3 and the other grantholder. He seems to be a rather well-integrated member of the department, and he is interested in staying in Sweden. His willingness to stay is influenced by the possibility of "affect[ing] the development of things" in the workplace, as he describes in the interview (11). 
(11) In my country, people are expected to do what they are told, but here you are one of the owners, and I like this. Here you can affect the development of things.

In terms of language choice, Informant 4 repeatedly mentions that he likes using English for professional purposes because he finds it an efficient way of getting things done and understanding others better. In fact, efficiency is a term he mentions frequently in his interview, which suggests its value (12). Thus, he communicates in English at work, especially in writing (e.g. emails, literature, papers, etc.), although he speaks his mother tongue with his fellow nationals (13). Again, efficiency seems to be the main reason for his language choice. An interesting comment he makes is that the grant-holder, who occupies one of the positions of power, encourages people to use English. This is relevant in that a specific language (English) is explicitly associated with a person who has the potential to influence others, establishing a clear link between English and power in the department.

(12) Using English at work is more efficient [...] the grant-holder encourages us to speak English [...] I agree with this; I think we need to speak more English.

(13) At work it is also common to use my mother tongue; only when it is more efficient, and there are no other people around.

In addition, Informant 4 mentions that Informant 3 encourages him to learn Swedish, but he does not consider his proficiency to be high enough for Swedish to be an efficient way to communicate at work (14). Again, as in the case of English, a prominent figure in the department endorses the use of a specific language (Swedish), which may load its ideological significance.

(14) My Swedish is too basic, it helps outside the department but I do not really speak Swedish.

Social interaction, however, seems to occur consistently in Informant 4's mother tongue. He tells us that he socializes mostly with colleagues from work and other connections with a similar background; they usually go to the gym or to karaoke bars. He explains this in relation to shared background, habits, and interests (15).

(15) There is a really large Asian group here [...] We share our language, our culture, and our interests.

As an example of the significance of the Asian community in which Informant 4 lives, he tells us the story of a technician from Asia who works at the department. Upon arrival, this technician could not interact with the other speakers of his language because he spoke a different variety. For a while, they communicated in 
English, but through an active teaching effort by his co-workers the newcomer gradually learnt the variety used as a lingua franca within their group, and they now communicate in that language.

The only exception to Informant 4's language of choice for socialization (his mother tongue) is lunchtime at work. Given that Informant 4 conducts his research within the research project directed by Informant 3, he occasionally has lunch with the project's team at the restaurant. At such times, he uses English, as that is the language everyone speaks in that group. However, as his words illustrate (16), Informant 4 does not necessarily see these meals as mere socialization venues; for him, they are opportunities to get things done.

(16) Informant 3 encourages people to come along and discuss stuff [...] they are very busy, but they have to eat every day.

\subsection{Informant 5}

Informant 5 is a researcher from Central Europe who arrived in Sweden as a $\mathrm{PhD}$ student six years ago. He is now a postdoc researcher and had worked with Informant 3 for almost a year at the time of the interview. Because his current position is of a temporary nature, he is applying for positions in Europe, but would rather stay in Sweden.

In relation to social interaction at work, Informant 5 usually has lunch at the restaurant with the other members of the research group. His reports about language choices during lunch breaks are consistent with those of the other interviewees, i.e. English is the main language but, given the international nature of this group, other languages may be used too $(17,18)$. His approach might be influenced by Informant 3's views on languages and cultures.

(17) We sometimes use Swedish just to keep the good spirits.

(18) Many things can happen regarding languages.

Another venue for social interaction is the office. There, again, his description coincides with Informant 1, one of the colleagues he shares the office with. English is still the most commonly used language, especially because different languages are represented by individual speakers in the office; however, he acknowledges that, especially at the beginning, it is hard for people to use English all the time. In his view, there is no way around this situation and, in time, English comes more naturally (19). 
(19) It is hard at the beginning, when you come from another country [...] it can be hard to use English all the time [...] nobody can avoid English in this department.

Informant 5's interest in languages may be partly connected to his language background and family history: in his childhood he lived in different Central European countries, and he can speak four languages. Nevertheless, his language choices seem to be well defined, especially at the department. For Informant 5, English is the default language for work (20), and he considers this is the most sensible language choice.

(20) Here everything is written in English; it's better for everyone, so everyone can have access to everything.

It is interesting that Informant 5 sees English as the language that allows everyone access to information, especially because he works at a public university in Sweden. Of course, his views regarding this issue are motivated by the international character of his department, rather than by the geographical context.

\subsection{Summary: language, lunch, and socialization}

As shown above, a key activity for social interaction that emerges across the participants is lunch. Although not the only opportunity for socialization (which seems to occur both in and outside the office; see Informants 1 and 4), lunch seems to serve two key communicative functions: (a) it provides the opportunity for informal exchange of information, and (b) it allows for small talk and establishment of social relations at work. The activity of lunch is closely tied to settings, participants, and relationships: where lunch takes place, who is present, and the relationships among them. All these aspects influence language practices and socialization patterns. The place where lunch occurs partially determines who participates in this activity; in turn, existing relationships among people also determine where lunch takes place, and who is present. In this dynamic of social interactions, language seems to be construed as a key factor in the participants' language choices and their ability to engage in informal talk. Language, place, and people involved seem to be the primary factors in language clustering, i.e. the creation of groups that interact socially on a regular basis (see Figure 2). Both in terms of people and place, English plays a major role, either by its status as the lingua franca or by being the language that is avoided. 


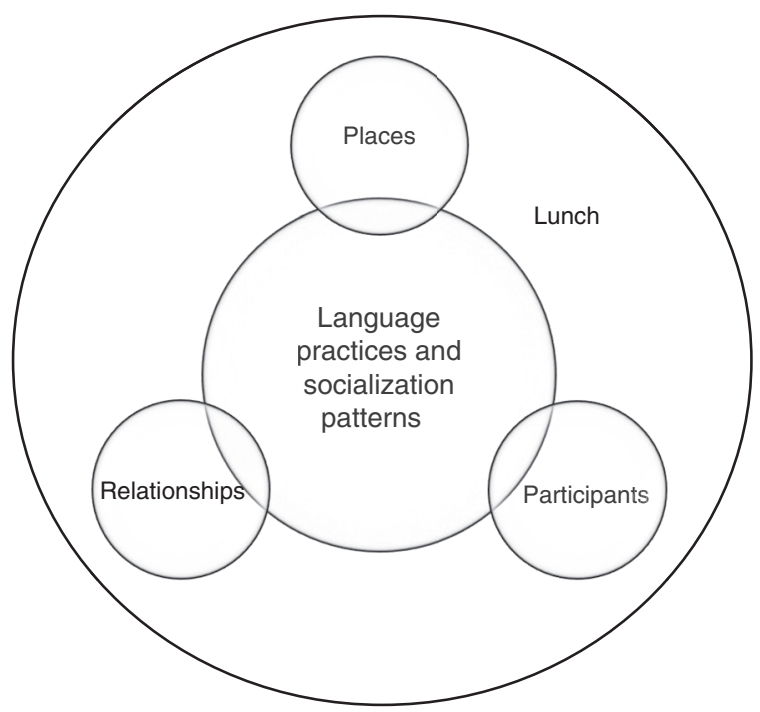

Figure 2: Interplay of factors influencing social interaction and language clustering

\section{Discussion}

In this section, we will summarize and discuss language practices adopted during social interaction in a multilingual academic workplace, using the concepts of language clustering and thin communication (Tange \& Lauring 2009) to frame our observations. This study has some obvious limitations: the small sample size, the fact that participants work very closely, and the fact that the data comes exclusively from the participants' reported experiences. Nevertheless, this research was designed as an exploration to set the basis for possible further studies and to determine which key activities and practices have potential for future investigation. As elicited from the interviews, in this department there is a group of people who go for lunch to a restaurant on campus; these people usually communicate in English, although at times they use Swedish. This group includes two powerful members of the department, namely the Head (Informant 3) and the main grantholder. On the other hand, some people prefer to have lunch in the lunchroom; in this context, language choice seems to follow an organic pattern, i.e. the suitable language is selected depending on who is present. Further studies could triangulate a larger pool of interviews with participant observation, and possibly analysis of interactions.

Our first aim was to explore the relationship between language practices and social interaction. In our context, language practices both reflect and create social 
clustering, possibly in connection to dynamics of power and language ideologies (see Lønsmann 2014: 92). The language clustering phenomenon, first observed by Marschan-Piekkari et al. (1999), is typically associated with informal gatherings, which in our case is reflected in the lunch activity. Because everyone needs to fulfill this physiological need, lunch forces people to interact socially and, therefore, to make a choice in terms of language. In our study, language practices become associated with two social groups (as described by our participants): those affiliated with the Swedish/ELF group have lunch at the restaurant, while a more heterogeneous group, mostly composed of Asians and ELF speakers, has lunch in the lunchroom. Although the characteristics of this language clustering phenomenon are similar to those identified in organizational business settings, our informants do not suggest a highly imbalanced situation of exclusion and division tied to rigid structures of power. Rather, we could speak of "mutually excluding groups" (Angouri 2014: 6), where common-sense, everyday language uses flow into different social bonds.

At the same time, while some of our informants with key roles in the department seem to have some awareness that these practices hinder socialization (see our title), dimensions of power and ideology may explain why they persist. Departing from Bordieu's theories, Tange \& Lauring (2009) contend that language clustering creates a situation where specific languages - in our case English and Swedish - acquire "symbolic power": being able to master these languages provides opportunities and access to important contexts for socialization. As acknowledged by Informant 4 (12), lunch at the restaurant can be an important venue for informal discussion of professional topics; this provides a motivation to use English for social interaction for those employees who wish to establish themselves in the department. Furthermore, the "restaurant group", composed mostly of Europeans or staff in general who have permanent residence in Sweden, seems to share implicit expectations that people should be willing to learn and use not only English but also Swedish (see 8, 9, and 18). These remarks echo Lønsmann's (2014: 113) observations about the key role that language ideologies play in creating and reaffirming hierarchical structures in a workplace, especially when a local language is also construed as valuable and desirable:

the local version of the "one nation, one language" ideology contributes to the processes of exclusion by constructing Danish as the only natural language in Denmark and by creating boundaries between "Danes" and "foreigners" and between foreigners who display an interest in learning Danish and those who do not. A consequence of this language ideology is that Danes are less likely to switch to English in interactions with internationals who have been in Denmark longer than a few months since they are supposed to have learnt Danish. 
As suggested by Informant 4's remark reported above (12) language clustering entails issues of thin communication and containment of information; this uneven flow of information seems to affect both social groups, with much information being exchanged among the Asian collaborators in their mother tongue (13). Nevertheless, maybe in combination with the language ideologies as discussed above, it is undeniable that few new people join the prestige "restaurant group", especially on a regular basis. The information rewards offered by interacting with this prestige group may not be strong enough to motivate those who feel uncomfortable about using English or the local language informally (6) or (14), for example, "fearing perhaps that [their linguistic weaknesses] reflect badly on their professional competence" (Tange \& Lauring 2009: 224). These remarks once again suggest an awareness of the fact that nonnative speakers' fluency in English is often grounds for (negative) evaluation (Śliwa \& Johansson in press), with potential consequences in terms of power distribution and inequality of treatment. Overall, we can suggest that language clustering, in combination with possible avoidance strategies, limits the establishment of informal channels for the dissemination of information, which as shown by Lauring and Selmer (2011), are important to build a positive social climate in the workplace.

Interestingly enough, language choices in informal communication stand in clear contrast to technical, formal communication in our sample. English is the main disciplinary language: as such, it is the language "everyone can have access to" (19); its use is rather uncontested across all our participants and it seems to carry an ethos of inclusion for professional communication (Angouri and Miglbauer 2013; Fredriksson et al. 2006). This can be explained in relation to the concept of company speak (Welch et al. 2005): in our case, the technical language of the scientific discipline, "discipline speak", is available to all our participants. For instance, both our Asian informants mentioned that technical and professional communication in English was not a problem $(5,11)$, but that informal communication and "small talk" could be challenging, and that in any case writing, rather than speaking, is preferred.

The experiences presented in this exploratory study connect to the issues of language as a vehicle for rapport management in intercultural contexts addressed by Spencer-Oatey (2002) and Spencer-Oatey and Xiong (2006) among others. It was rather evident from the descriptions of the informants belonging to the "restaurant group" that informal communication and socialization, occurring primarily during lunch, are highly valued, and that they are perceived as part and parcel of their professional identity. The other participants also valued social interaction, but they seem to privilege a professional identity of efficiency, with 
socialization occurring outside work and with people from the same cultural background. These dynamics echo Spencer-Oatey's (2000, 2002) call for attention to potential cultural differences as reflected in different expectations about rights and obligations tied to one's professional role (social identity), resulting in different strategies to manage rapport and deal with threats to maintaining face, and different weight placed on positive interpersonal relationships. These issues would however require further investigation.

Overall, our study highlights that informal communication in a multilingual academic workplace also serves the purpose of establishing social bonds and exchanging information among employees. Some patterns of clustering and thin communication emerge, potentially as a reflection and a construction of the symbolic power of certain languages and underlying language ideologies, although further research on this point would be necessary. At the same time, it seems that these dynamics affect everybody in the workplace, including individuals with a higher status in the department's hierarchy. Furthermore, individuals' professional goals and priorities seem to be a key determinant in the adoption of socialization and language practices: while some see their presence as rather transient, others may wish to stay, and may therefore socialize with people who have similar goals. On the other hand, because of the group/ language division identified, we can see that people with similar goals (e.g. staying in Sweden or not) converge toward the same language practices. This situation resonates with Baker's (2011) arguments about the complexity of examining intercultural communication in actual contexts, since many layers of social stratifications tied to individuals' objectives and perceptions often overlap.

\section{Concluding remarks}

Our study addresses the existing gap in the literature on the role of English and other language practices for social interaction in an academic multilingual workplace. Drawing from ethnographic interviews with a representative sample at a Swedish University, our results unveil that language practices are tied to socialization patterns in such a context. As mentioned in previous studies (e.g. Marschan-Piekkari et al. 1999; Tange 2012a, 2012b; Tange \& Lauring 2009), language choices do not occur in a vacuum; instead, they entail implications in terms of identity and power relations. These issues are not always explicit, but 
emerge in relation to language practices in informal communication and small talk, which are key in the establishment of rapport: "Too frequently, relationally oriented communication at work is eschewed over task-related communication" (Keyton et al. 2013: 164). Although dynamics of clustering and thin communication (Tange \& Lauring 2009) surface, the study also emphasizes that language practices need to be studied in context, since "participants adapt their choices to local needs and conditions” (Söderlundh 2012: 105). Assumptions about power and ideology in relation to language use and socialization need to be carefully balanced against individuals' goals and motivations. Echoing studies in university settings showing that language practices vary considerably depending on context and discipline (Bolton \& Kuteeva 2012; Kuteeva 2014; Kuteeva \& Airey 2013), we can see similarities in the way our informants consider English to be the technical language in their discipline. However, we can also see differences beyond disciplinary practices, tied to each individual's career goals and personal motivations (e.g. length of stay in the country, type of position, personal connections).

In closing, we can invoke the suggestions made by researchers to carefully analyze multilingual communicative situations in a context-sensitive fashion. This approach can minimize assumptions about the relationship between language and power, as well as the dangers connected to a straightforward (and stereotyped) association between language and culture (Baker 2011). While we might agree with Tange (2012b: 14) that "the English language - as the preferred medium of global scholarship - carries more symbolic power, and ... has made it increasingly difficult for employees to admit to linguistic weakness", language may also be a choice of convenience; as mentioned by Informant 5 , in this department the choice of English is tied to the international character of the workplace, but other languages are used when they are more contextually relevant. In other words, the connection between language and power depends more on the people who use it than the language itself. If anything, across multilingual workplaces it seems important to "raise the awareness of language issues among employees" (Lønsmann 2014: 113); these issues should be discussed rather than ignored. In a multilingual workplace there needs to be an active agenda for promoting employees' awareness of the importance of socialization and informal communication to establish rapport (Pullin 2010; SpencerOatey 2002). In relation to this, it might be beneficial to demystify the prestige of English and the ideology of nativeness (Kuteeva 2014), especially in informal communicative situations: "policing”, "correcting”, and upholding standards of perfection may be counter-productive and discourage people to socialize and communicate, especially when cultural differences may be at the root of 
perceptions of threats to maintaining face and of professional identity (SpencerOatey 2006).

\section{References}

Airey, John. 2011. Talking about teaching in English: Swedish University lecturers' experiences of changing their teaching language. Ibérica 22. 35-54.

Angouri, Jo. 2010. "If we know about culture it will be easier to work with one another": Developing skills for handling corporate meetings with multinational participation. Language and Intercultural Communication 10(3). 206-224. DOI: 10.1080/14708470903348549

Angouri, Jo. 2012. Managing disagreement in problem solving meeting talk. Journal of Pragmatics 44(12). 1565-1579.

Angouri, Jo. 2014. Multilingualism in the workplace: Language practices in multilingual contexts. [Special issue: multilingualism at work.] Multilingua 33(1-2). 1-9. DOI: 10.1515/multi-2014-0001

Angouri, Jo \& Francesca Bargiela-Chiappini. 2011. "So what problems bother you and you are not speeding up your work?” Problem solving talk at work. Discourse \& Communication 5(3). 209-229.

Angouri, Jo \& Marlene Miglbauer. 2013. Local languages and communication challenges in the multinational workplace. In Farzad Sharifian \& Maryam Jamarani (eds.), Language and intercultural communication in the new era, 225-245. New York \& London: Routledge.

Baker, Will. 2011. Intercultural awareness: Modelling an understanding of cultures in intercultural communication through English as a lingua franca. Language and Intercultural Communication 11(3). 197-214.

Björkman, Beyza. 2011. Pragmatic strategies in English as an academic lingua franca: Ways of achieving communicative effectiveness. Journal of Pragmatics 43(4). 950-964.

Björkman, Beyza. 2013. English as an academic lingua franca. Berlin \& New York: Mouton de Gruyter.

Björkman, Beyza. 2014. Language ideology or language practice? An analysis of language policy documents at Swedish Universities. [Special issue on English in the Language Ecology of Northern Europe.] Multilingua 33(3-4). 335-363. DOI: 10.1515/multi-2014-0016

Bjørge, Anne-Kari \& Sunniva Whittaker. 2011. Language management within Norwegian organizations with a multicultural workforce. FOCUS working paper: SNF/NHH.

Bolton, Kinglsey \& Maria Kuteeva. 2012. English as an academic language at a Swedish University: Parallel language use and the "threat" of English. Journal of Multilingual and Multicultural Development 33(5). 429-447. DOI: 10.1080/01434632.2012.670241

van den Born, Floor \& Vesa Peltokorpi. 2010. Language policies and communication in multinational companies: Alignment with strategic orientation and human resource management practices. Journal of Business Communication 47(2). 97-118. DOI: $10.1177 / 0021943610364515$

Bourdieu, Pierre. 1991. Language and symbolic power. Cambridge, MA: Harvard University Press. 
Canagarajah, Suresh. 2013. Agency and power in intercultural communication: Negotiating English in translocal spaces. Language and Intercultural Communication 13(2).

202-224.

Charles, Mirjaliisa. 2007. Language matters in global communication. Journal of Business Communication 44(3). 260-282.

D'Andrade, Roy. 1976. Propositional analysis of US American beliefs about illness. In Keith H. Basso \& Henry A. Selby (eds.), Meaning in anthropology. Albuquerque, NM: University of New Mexico Press.

Dörnyei, Zoltan \& Kata Csizér. 2011. How to design and analyze surveys in second language acquisition research. In Alison Mackey \& Susan Gass (eds.), Research methods in second language acquisition: A practical guide, 74-94. Chichester, West Sussex (UK): Wiley-Blackwell.

Fredriksson, Riikka, Wilhelm Barner-Rasmussen \& Rebecca Piekkari. 2006. The multinational corporation as a multilingual organization: The notion of a common corporate language. Corporate Communications: An International Journal 11(4). 406-423.

Gunnarson, Britt-Louise. 2001. Swedish, English, French or German - The language situation at Swedish Universities. In Ulrich Ammon (ed.), The dominance of English as a language of science: Effects on other languages and other communities, 287-316. Berlin \& New York: Mouton de Gruyter.

Gunnarson, Britt-Louise. 2009. Professional discourse. London: Continuum.

Hazel, Spencer \& Janus Mortensen. 2013. Kitchen talk-exploring linguistic practices in liminal institutional interactions in a multilingual university setting. In Hartmut Haberland, Dorte Lønsmann \& Bent Preissler (eds.), Language alternation, language choice and language encounter in international tertiary education, 3-30. Netherlands: Springer.

Holstein, Jaber \& James Gubrium. 1997. Active interviewing. In David Silverman (ed.), Qualitative research: Theory, method and practice, 113-129. Thousand Oaks, CA: Sage.

Hult, Francis. 2012. English as a transcultural language in Swedish policy and practice. Tesol Quarterly 46(2). 230-257. DOI: 10.1002/tesq.19

Johnson, Jeffrey (ed.). 1990. Selecting ethnographic informants (Qualitative Research Methods). Newbury Park, CA: Sage.

Johnson, Jeffrey \& Stephen Weller. 2002. Elicitation techniques for interviewing. In Jaber Gubrium \& James Holstein (eds.), Handbook of interview research, 185-204. Thousand Oaks, CA: Sage.

Keyton, Joann, Jennifer Caputo, Emily Ford, Rong Fu, Samantha Leibowitz, Tingting Liu, Sarah Polasik, Paromita Gosh \& Chaofan Wu. 2013. Investigating verbal workplace communication behaviors. Journal of Business Communication 50(2). 152-169.

DOI: $10.1177 / 0021943612474990$

Kuteeva, Maria. 2013. English in academic and professional contexts: Editorial. [Special issue on English in academic and professional contexts.] Nordic Journal of English Studies 12(1). 1-6.

Kuteeva, M. 2014. The parallel language use of Swedish and English: The question of "nativeness" in University policies and practices. Journal of Multilingual and Multicultural Development. DOI: 10.1080/01434632.2013.874432

Kuteeva, Maria \& John Airey. 2013. Disciplinary differences in the use of English in higher education: Reflections on recent language policy developments. Higher Education. DOI: $10.1007 /$ s10734-013-9660-6

Lauring, Jakob. 2007. Language and ethnicity in international management. Language and Ethnicity 12. 255-266. DOI: 10.1108/13563280710776851 
Lauring, Jakob \& Jan Selmer. 2011. Social climate in diverse university departments: The role of internal knowledge sharing. Educational Research 53(3). 347-362. DOI: 10.1080/ 00131881.2011 .598662

Locher, Miriam \& Richard Watts. 2005. Politeness theory and relational work. Journal of Politeness Research. Language, Behaviour, Culture 1(1). 9-33.

Lønsmann, Dorte. 2014. Linguistic diversity in the international workplace: Language ideologies and processes of exclusion. [Special issue: multilingualism at work.] Multilingua 33(1-2). 89-116. DOI: 10.1515/multi-2014-0005

Marschan-Piekkari, Rebecca, Denice Welch \& Lawrence Welch. 1999. In the shadow: The impact of language on structure, power and communication in the multinational. International Business Review 8(4). 421-440. DOI: 10.1016/S0969-5931(99)00015-3

McEnery, Anthony, Richard Xiao \& Yukio Tono. 2006. Corpus-based language studies. An advanced resource book. London \& New York: Routledge.

Miles, Matthew \& Michael Huberman. 1994. Qualitative data analysis: An expanded sourcebook. Thousand Oaks, CA: Sage.

Mortensen, Janus \& Hartmut Haberland. 2012. English - The new Latin of academia? Danish universities as a case. International Journal of the Sociology of Language 216. 175-197. DOI: $10.1515 /$ ijsl-2012-0045

Nelson, Marie. 2014. "You need help as usual, do you?" Joking and swearing for collegiality in a Swedish workplace. [Special issue: multilingualism at work.] Multilingua 33(1-2). 173-200. DOI: 10.1515/multi-2014-0008

Peltokorpi, Vesa \& Eero Vaara. 2012. Language policies and practices in wholly owned foreign subsidiaries: A recontextualization perspective. Journal of International Business Studies 43(9). 808-833. http://dx.doi.org/10.1057/jibs.2012.28

Preisler, Bent. 2003. English in Danish and the Danes' English. The International Journal of the Sociology of Language 159. 109-126.

Pullin, Patricia. 2010. Small talk, rapport and international communicative competence: Lessons to learn from BELF. Journal of Business Communication 47(4). 455-476.

Rogerson-Revell, Pamela. 2007. Using English for international business: A European case study. English for Specific Purposes 26. 103-120.

Rogerson-Revell, Pamela. 2008. Participation and performance in international business meetings. English for Specific Purposes 24. 401-421.

Söderlundh, Hedda. 2012. Global policies and local norms: Sociolinguistic awareness and language choice at an international university. The International Journal of the Sociology of Language 216. 87-109. DOI: http://dx.doi.org/10.1515/ijsl-2012-0041

Spencer-Oatey, Helen. 2000. Rapport management: A framework for analysis. In Helen SpencerOatey (ed.), Culturally speaking. Managing rapport through talk across cultures, 11-46. London, UK: Continuum.

Spencer-Oatey, Helen. 2002. Managing rapport in talk: Using rapport sensitive incidents to explore the motivational concerns underlying the management of relations. Journal of Pragmatics 34. 529-545.

Spencer-Oatey, Helen. 2006. Theories of identity and the analysis of face. Journal of Pragmatics 39(4). 639-656.

Spencer-Oatey, Helen \& Zhaoning Xiong. 2006. Chinese students' psychological and sociocultural adjustments to Britain: An empirical study. Language, Culture and Curriculum 19(1). 37-53.

Spolsky, Bernard. 2004. Language policy. Cambridge: Cambridge University Press. 
Spradley, James. 1979. The ethnographic interview. New York: Holt, Reinhart \& Winston.

Sweeney, Emma \& Zhu Hua. 2010. Accommodating toward your audience: Do native speakers of English know how to accommodate their communication strategies toward nonnative speakers of English? Journal of Business Communication 47(4). 477-504.

Śliwa, Martyna \& Marjana Johansson. in press. How non-native English speaking staff are evaluated in linguistically diverse organizations: A sociolinguistic perspective. Journal of International Business Studies, in press.

Tange, Hanne. 2010. Caught in the tower of Babel: University lecturers' experiences with internationalization. Language and Intercultural Communication 10(2). 137-149.

Tange, Hanne. 2012a. Organising language at the international university: Three principles of linguistic organization. Journal of Multilingual and Multicultural Development 33(3). 287-300. DOI: 10.1080/01434632.2012.661735

Tange, Hanne. 2012b. Wars of words: Management policy and employee practice at the international university. Tamara, Journal of Critical Organization Inquiry 10(4). 5-15.

Tange, Hanne \& Jakob Lauring. 2009. Language management and social interaction within the multilingual workplace. Journal of Communication Management 13(3). 218-232.

Welch, Denice, Lawrence Welch \& Rebecca Piekkari. 2005. Speaking in tongues. The importance of language in international management processes. International Studies of Management \& Organisation 35. 10-27. 